\section{RSBMT: VERSÃO ON-LINE}

Visite O SITE da Revista da Sociedade Brasileira de Medicina Tropical na Internet. Nele você encontrará os números atuais da Revista na Versão on-line, trazendo todos os artigos publicados na íntegra, além de números anteriores.

O endereço é http:www.scielo.br/rsbmt

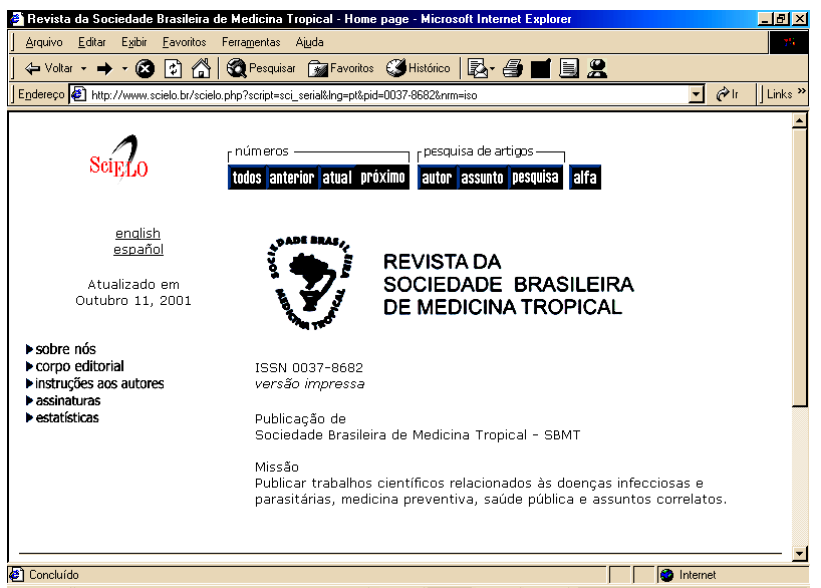

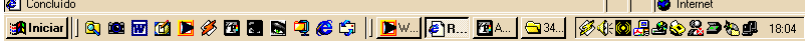

\section{CONGRESSO}

\section{- IV CONGRESSO DA SOCIEDADE BRASILEIRA DE DOENÇAS SEXUALMENTETRANSMISSIVEIS}

Será realizado no período de 1 a 4 de setembro o IV Congresso da Sociedade Brasileira de Doenças Sexualmente Transmissíveis em Manaus, Amazonas.

O Comitê Científico selecionará os trabalhos para apresentação oral e pôster. O resumo deverá ser preparado conforme modelo anexo, obedecendo as normas a seguir:

- Formulários sem rasuras, borrões ou uso de corretivo, utilizando somente a área contida dentro dos limites de $15 \mathrm{~cm}$ de largura por $20 \mathrm{~cm}$ de altura.

- Texto digitado em word (6.0 ou 7.0) para WINDOWS; fonte New Times Roman, tamanho 10; espaço entre linhas simples e papel tamanho A4 (210x297mm).

- Cada trabalho deverá vir acompanhado do original em 3 vias de boa qualidade e acompanhado de disquete 3.5 contendo o resumo.

- Título em caixa alta.

- Nome de autores, também em caixa alta.

Ex: VIEIRA, S.M.B.; TORRES FILHO, J.E.; GONÇALVES, P.E.
- Nome da instituição.

- Endereço para correspondência; Rua/Av, número, complemento, bairro, cidade, UF, cep e e-mail.

- O resumo deverá obedecer a seguinte estrutura: introdução, objetivo, metodologia, resultado, discussão e conclusão.

- Data limite para postagem dos resumos: 20 de maio de 2002.

- Não serão aceitas inscrições de trabalho via fax.

- Data prevista para divulgação dos resultados de seleção: 20 de julho de 2002.

- O premio Cientifico Dr. Alfredo Augusto da Matta, de $R \$ 1.500,00$, será entregue para o melhor trabalho em cada área temática.

- Para maiores informações entrar em contato com:

Orcal Pesquisas \& Eventos Ltda.

Av. Joaquim Nabuco, 352 - Centro - CEP 69.020-031

Manaus- AM - Brasil

Fone: (0xx92) 622-3377

Fones/Fax: (0xx92) 232-4468 e (0xx92) 234-5063

E-mail: orcal@osite.com.br

\section{- XXV CONGRESSO BRASILEIRO DE HEMATOLOGIA E HEMOTERAPIA}

O Congresso Nacional da SBHH que ocorrerá em Salvador, de 26 a 30 de maio de 2002 será um evento á altura do desenvolvimento da Hematologia/Hemoterapia brasileiras neste terceiro milênio.

Estão programados diversos cursos pré-congresso - HLA, Triagem Clínica de Doadores, Aférese, Hemostasia, Enfermagem em Hematologia e Hemoterapia - e a programação científica já conta com a presença confirmada de todos os grandes especialistas brasileiros na área, e de alguns dos maiores nomes da Hematologia e Hemoterapia mundiais, muitos deles vindo pela primeira vez ao nosso país. Estão confirmados Paul Holland, Celso Bianco, Roberto Villaescusa Collazo, Morris Blajchman, Erick Preston, Elliot Vichinsky, Sergio Giralt, Vanderson Rocha, David Kutter, entre muitos outros convidados estrangeiros.

Haverá ainda diversos eventos paralelos, como Simpósio de Captadores, Simpósio de Odontologia, Encontro de Administradores de Serviços de Hemoterapia, Simpósio de Enfermagem, além do $1^{\circ}$ Congresso Brasileiro de Hematologia Pediátrica.

A programação social será um capítulo à parte, e honrará a tradição festeira e de hospitalidade da Bahia.

Marque na sua agenda e não perca esta oportunidade de aperfeiçoamento, reciclagem e congraçamento.

Para informações adicionais:

Eventus System Ltda. - Rua Oito de Dezembro, 547 Graça - 40150-000 Salvador - Bahia - Brasil. Tel.: (55 71) 264.3477 Fax: (55 71) 264.0508 e-mail: informa@eventussystem.com.br 


\section{SIMPOSIO}

\section{- IV INTERNATIONAL SYMPOSIUM ON PHELOBOTOMINE SANDFLIES}

03 a 07 de agosto de 2002

\section{LOCAL}

Bahia Othon Palace Hotel

\section{SECRETARIA EXECUTIVA}

Eventus System Ltda. - Rua Oito de Dezembro, 547. Graça - 40150-000 Salvador - Bahia - Brasil. Tel.: (55 71) 264.3477 - Fax: $(55$ 71) 264.0508 e-mail: informa@eventussystem.com.br

\section{SESSÃO SOLENE DE ABERTURA}

A Sessão Solene de Abertura ocorrerá no dia 03 de agosto de 2002, às 20h, no Bahia Othon Palace Hotel.

\section{INSCRIÇÕES}

As inscrições poderão ser feitas pelo correio ou na Secretaria do evento até o dia 03 de julho de 2002. Após esta data as inscrições poderão ser feitas no local do evento a partir das 14h, do dia 03 de agosto.

\section{IDIOMA OFICIAL}

O idioma oficial do 4th Symposium International on Phlebotomine Sandflies é o inglês.

\section{TRADUÇÃO SIMULTÂNEA}

Haverá tradução simultânea inglês/português/inglês.

\section{TEMAS LIVRES}

O prazo de entrega dos temas livres é 05 de fevereiro de 2002. Porém, se você desejar concorrer a uma passagem aérea e hospedagem para vir ao simpósio, envie o seu trabalho até o dia 15 de dezembro de 2001.

\begin{tabular}{|l|c|l|}
\cline { 2 - 3 } \multicolumn{1}{c|}{} & Até $05 / 03 / 2002$ & Após05/03/2002 \\
\hline Participantes & US\$150,00 & A ser definido \\
\hline Acompanhantes & US\$100,00 & A ser definido \\
\hline
\end{tabular}

\section{- SBMT SÓcIOS HOMENAGEADOS}

Durante o XXXVIII Congresso da Sociedade Brasileira de Medicina Tropical, realizado em Foz do Iguaçu, Paraná, entre os dias 24 a 28 de fevereiro de 2002, três sócios da Sociedade Brasileira de Medicina Tropical foram homenageados com Menção Honrosa pelo Centenário da Organização Pan-Americana de Saúde. Os homenageados foram escolhidos pelo Conselho do Centenário da OPAS-Brasil, pela determinação, conhecimento e dedicação à saúde pública no Brasil. Os sócios homenageados foram o Dr. Francisco de Paula Pinheiro, Dr. Antonio Carlos da Silveira e Dr. Pedro Luiz Tauil por suas contribuições específicas nas áreas de epidemiologia e controle das arboviroses, da doença de Chagas e da malária, respectivamente. Foram também homenageados o Programa Nacional de Imunizações da Fundação Nacional de Saúde, do Ministério da Saúde, pelo seu excelente desempenho na prevenção de doenças imunopreveníveis e eliminação da poliomielite e do sarampo; e a Secretaria de Saúde do Estado do Amazonas, pelo grande êxito na redução da incidência da malária naquele Estado, nos anos 2000 e 2001. 